\title{
Treatment of Tourette Syndrome
}

\author{
Roger M. Kurlan
}

Published online: 17 September 2013

(C) The American Society for Experimental NeuroTherapeutics, Inc. 2013

\section{Introduction}

Tourette syndrome (TS), also known as Gilles de la Tourette's syndrome or Tourette disorder, is a childhood-onset condition characterized by chronic motor and phonic tics. Simple motor tics consist of brief twitches or jerks, such as eyeblinking, facial grimacing or head jerks. More complicated or coordinated movements, like touching, tapping or jumping, are considered to be complex motor tics. Simple phonic tics are inarticulate noises or sounds such as throat clearing, sniffing and grunting, while complex phonic tics have linguistic meaning and consist of partial words, full words or phrases. Coprolalia (obscene words or insults) is an example of a type of complex phonic tic, and while responsible for much of the public notoriety of TS, is present in only a minority of TS patients.

It has been estimated that about $1 \%$ of school-age children have TS. Some patients with TS have mild tics. In others, tics can be disabling by causing social embarrassment, low selfesteem, social isolation, and sometimes conflict with others (e.g., with verbal insults). Some tics are painful (e.g., neck jerks) and some can be self-injurious (e.g., scratching, picking, poking), even life-threatening [1]. Tics sometimes interfere with the flow of speech or actions.

TS is now viewed as a neuropsychiatric spectrum disorder in which the tics are commonly associated with attention deficit hyperactivity disorder (ADHD) and obsessive-compulsive disorder (OCD). For some patients, these behavioral comorbidities can be the major source of disability and should be considered to be important targets for treatment.

\section{Pathogenesis}

Ideally, the treatment of neurological movement disorders, including TS, is driven by an understanding of the underlying neurobiological mechanisms [2, 3]. From a historical perspective, it was the observed response of patients with TS in the 1950s and 1960s to antipsychotic dopamine receptor blocking drugs that led to a reconceptualization of TS as an organic, neurological and neurochemical disorder rather than one with
Invited Review for Movement Disorders Therapeutics, in NeuroTherapeutics, Jankovic J and Factor S (editors)

\section{R. M. Kurlan $(\square)$}

Movement Disorders Program, Atlantic Neuroscience Institute, Overlook Medical Center, 99 Beauvoir Avenue, Summit, NJ 07902, USA

e-mail: roger.kurlan@atlantichealth.org 
psychodynamic roots. These therapeutic observations also contributed to the notion that there is a state of increased dopamine neurotransmission in the brain that underlies TS. This so-called "dopamine hypothesis" of TS remains an active one today, but unfortunately the exact mechanisms have not been elucidated. A variety of neurochemical, neuropharmacological and functional neuroimaging studies have been carried out with the aim of sorting out whether increased dopamine signal transduction is indeed a primary mechanism leading to tics and, if so, whether there is an increased amount of synaptic dopamine (high tonic release, increased phasic release or increased innervation) or an increased sensitivity to the neurotransmitter (increased receptor number, increased receptor affinity, altered postsynaptic signaling). To date, research evidence has proven to be inconclusive in clarifying these possibilities.

Probably the most accepted current hypothesis regarding the underlying pathophysiology and pathological anatomy of TS is that there is an impairment of cortical inhibition of motor programs that are spontaneously generated in the basal ganglia and expressed as tics. In support of this notion, a repetitive transcranial magnetic stimulation study of patients with TS found reduced excitability of intracortical inhibition [4], suggesting that sensory inputs have an increased ability to stimulate motor outputs. This finding may represent a physiological correlate of the known clinical feature of TS that tics are often linked to premonitory sensations [5].

Volumetric brain MRI studies have identified cortical abnormalities in patients with TS, but structural localizations have been inconsistent, although several MRI studies have reported reduced caudate volumes [2]. Basal ganglia functional disturbances have also been identified in TS. Only a small number of postmortem TS brains have been examined pathologically. Two postmortem brain studies revealed a decrease in parvalbumin positive GABA neurons and cholinergic neurons in the striatum $[6,7]$. Further support for a disturbance of GABA neurotransmission comes from a recent positron emission tomography study that found abnormal binding of $\mathrm{GABA}_{\mathrm{A}}$ receptor binding in patients with TS compared to normal controls [8]. A variety of studies have reported disturbances in other neurochemical systems, including acetylcholine, glutamate, norepinephrine, histamine, opiates, adenosine and second messenger systems, but there is inadequate information to suggest new rational therapeutic approaches.

\section{Therapeutic Approach for Tics}

For people with TS who have mild and nondisabling tics, education about the condition and some supportive counseling are sufficient interventions. For children, a key focus is on maintaining and strengthening self-confidence and selfesteem in the face of TS. When tics are disabling, ticsuppressing therapy is indicated.

\section{Cognitive Behavioral Therapy for Tics}

Clinical trials have demonstrated tic-suppressing efficacy as a form of cognitive behavioral therapy called "habit reversal", which involves training patients to self-monitor their tics and premonitory sensations, and to respond to them by performing a voluntary behavior that is physically incompatible with the tic [9]. Potential shortcomings of habit reversal therapy are that it must be administered by a specially trained therapist so it is not widely available, it is time-consuming, and its longterm benefits have not been examined. There are concerns that having children mentally monitor and focus on their tics might detract from attentional abilities for more important tasks such as schoolwork. Some experts advocate trying this therapy first so that medications might be avoided. It may not be a satisfactory first line therapy for patients with severe tics. To date, cognitive behavioral and pharmacologic treatments have not been directly compared.

\section{Pharmacotherapy for Tics (Table 1)}

A number of recommendations and guidelines for the pharmacotherapy of TS have been published $[10,11]$. Due to the general paucity of class I and class II evidence, current treatment recommendations are often based on the personal experience of skilled clinicians and the variable regional availability of particular medications. The following represents a summary review and is influenced by the author's experience.

\section{Antipsychotic Medications}

The only FDA-approved medications for TS are the classical neuroleptic antipsychotic drugs, haloperidol and pimozide, which block D2 dopamine receptors. Their efficacy is supported by past controlled clinical trials, although these early trials often utilized nonstandard outcome measures. Long-

Table 1 Tic-suppressing medications

*FDA approved for this
indication
N.B. This list is not
comprehensive.

\begin{tabular}{|c|c|}
\hline Medication & $\underline{\text { Daily dose }(\mathrm{mg})}$ \\
\hline \multicolumn{2}{|l|}{ Alpha agonists } \\
\hline Clonidine & $0.05-0.5$ \\
\hline Guanfacine & $0.5-4$ \\
\hline \multicolumn{2}{|l|}{ Antipsychotics } \\
\hline Haloperidol* & $0.5-20$ \\
\hline Fluphenazine & $0.5-20$ \\
\hline Pimozide* & $0.5-10$ \\
\hline Risperidone & $0.5-16$ \\
\hline \multicolumn{2}{|c|}{ Dopamine depletor } \\
\hline Tetrabenazine & $12.5-100$ \\
\hline
\end{tabular}


term tic control typically requires chronic therapy. In a controlled trial of patients whose tics were controlled after 13 months of pimozide therapy, those in whom therapy was withdrawn (placebo group) relapsed (required an increase in drug dosage) after a mean of 37 days compared to 231 days in patients staying on the drug [12]. The most frequent side effects of these antipsychotic drugs are sedation, depression, increased appetite and parkinsonism. Fortunately, patients with TS treated with antipsychotics rarely develop tardive dyskinesia, possibly because the underlying state of their dopamine receptors is such that antagonist medications cannot induce the upregulation or increased sensitivity thought to underlie tardive dyskinesia [13]. Routine monitoring of the electrocardiogram is recommended when using pimozide because the drug can prolong the Q-T interval.

Randomized controlled trials have also supported the efficacy of the newer atypical antipsychotic risperidone for suppressing tics with similar magnitudes of benefit as the classical antipsychotics $[14,15]$. Observational data suggest that some of the other members of this drug class, such as aripiprazole and olanzapine, may likewise be effective in lessening tics. These drugs, however, carry the risk of tardive dyskinesia, albeit relatively small [16]. A large multicenter randomized controlled trial of aripiprazole for TS is currently in progress. While the atypical antipsychotics tend to have fewer motor complications, such as parkinsonism, they also commonly cause sedation and depression. It has become increasingly recognized that atypical antipsychotics often induce weight gain and glucose intolerance (metabolic syndrome), and these risks must be considered when selecting medications for patients with TS.

\section{Alpha Agonists}

Although antipsychotics have documented efficacy for suppressing tics, because of their frequent side effects, other medications are often used first. Several trials have supported efficacy of the alpha-2 adrenergic drugs clonidine and guanfacine $[17,18]$. The magnitudes of benefit reported are generally lower than for the antipsychotics, although no direct comparisons have been published. Since they also have efficacy for ADHD, the alpha agonists may be a good first-line choice for patients with both tics and ADHD. Common side effects of the alpha agonists are sedation, headache, dizziness, and irritability. Guanfacine is usually preferred because it tends to cause less sedation and can be given once (bedtime) or twice daily compared to 3-4 daily doses for clonidine. In my experience, a newer longer-acting form of guanfacine has proven to be less effective, possibly due to problems with absorption, and does not appear to have significant advantages over the original product. A transdermal form of clonidine is available and useful for children with problems swallowing pills.

\section{Other Medications}

Tetrabenazine is a drug that is a VMAT2 inhibitor and depletes presynaptic dopamine and has been reported to reduce tics $[19,20]$. Some clinicians recommend tetrabenazine as a first-line treatment for tics. The most common side effects of tetrabenazine are sedation, depression, insomnia, and restlessness [21]. The drug appears to have a low likelihood of causing tardive dyskinesia. Unfortunately, no comparison trials have been performed to determine the best initial medication.

A small clinical trial indicated that the antiepileptic agent that influences excitatory and inhibitory neurotransmission, topiramate, is effective for tics [22]. This drug can cause language and other cognitive side effects which might interfere with a child's learning. Dopamine agonists have been reported to reduce tics but a recent controlled clinical trial failed to show efficacy for pramipexole [23]. Other medications that have been described as being able to reduce tics include clonazepam, leviteracetam, and baclofen, but the evidence is limited and they are not commonly used.

Although it is common practice to combine drug classes, such as an alpha agonist and an antipsychotic, to suppress more severe tics, this approach has not been studied systematically. Although a number of nontraditional supplements and vitamins have been suggested to benefit TS, there is little scientific support for their use.

\section{Botulinum Toxin for Tics}

Local intramuscular injections of botulinum toxin is a therapeutic option when there are a few particularly bothersome tics. Case series indicate that botulinum toxin can not only reduce tics but also associated uncomfortable premonitory sensations and pain [24, 25]. Eyeblinking, neck and shoulder tics are the most common tics treated this way. Intralaryngeal injections are sometimes used for severe vocal tics. The benefits of botulinum toxin therapy are temporary, lasting 36 months.

Table 2 Treatment options for the common comorbidities

\begin{tabular}{ll}
\hline OCD & ADHD \\
\hline Cognitive behavioral therapy & Behavior therapy \\
Selective serotonin reuptake inhibitors & Alpha agonists \\
Atypical antipsychotics & Atomoxetine \\
Deep brain stimulation & Methylphenidate \\
\hline
\end{tabular}

$O C D$ obsessive-compulsive disorder, $A D H D$ attention deficit hyperactivity disorder 


\section{Deep Brain Stimulation Surgery for Tics}

In the past few years, deep brain stimulation (DBS) has been used for TS patients with disabling and medication-refractory tics. The results of double-blind, cross-over (with stimulation on or off) trials involving thalamic stimulation indicate that some patients can achieve substantial benefit [26, 27]. However, the best patient selection criteria and the optimal location for the electrodes (thalamus, globus pallidus interna, putamen, subthalamic nucleus and other areas have been used) in TS have not been established [28]. Potential complications associated with DBS include stroke, infection and side effects during stimulation, such as paresthesias, visual symptoms and dysarthria. Some patients with TS and self-harming tics/compulsions caused damage to their DBS hardware or caused infections by picking, scratching or digging at it, which should be taken into consideration when selecting patients for the procedure.

\section{Treatment of Behavioral Comorbidities}

A very important aspect of optimally managing patients with TS is to treat psychiatric comorbidities appropriately (Table 2). Cognitive behavioral therapy, selective serotonin reuptake inhibitors (SSRIs) and atypical antipsychotics are established therapies for OCD. Deep brain stimulation surgery involving the nucleus accumbens is being studied for severe cases of OCD. Since stimulants can induce tics, it had been recommended that these drugs should be avoided in children with ADHD who have tics or even a family history of tics. Randomized, blinded and placebo-controlled trials have shown, however, that at least the stimulant methylphenidate does not exacerbate tics in children with TS and is effective in treating coexisting ADHD [29, 30]. A variety of methylphenidate formulations are now available, including long-acting oral agents and skin patches. Other types of stimulants, such as dexedrine and mixed amphetamine salts, have not been studied in patients with TS. The selective norepinephrine reuptake inhibitor atomoxetine has been shown to improve ADHD symptoms without worsening of tics in children with both conditions [31].

Given the fact that many TS patients require treatment for both tics and comorbidities, combination therapy with ticsuppressing, anti-OCD and anti-ADHD medications is commonly employed. No formal assessments of such combination therapy have been reported. A useful treatment algorithm for treating patients with TS has recently been published [2].

A variety of other comorbidities, including mood, anxiety, impulse control and sleep disorders can occur with TS. A discussion of treatment for these conditions is beyond the scope of this article.
Required Author Forms Disclosure forms provided by the authors are available with the online version of this article.

\section{References}

1. Cheung M-YC, Shahed J, Jankovic J. Malignant Tourette syndrome. Movement Disord. 2007; 22(12):1743-50.

2. Jankovic J, Kurlan R. Tourette syndrome: Evolving concepts. Movement Disord. 2011; 26(6):1149-56.

3. Bronfeld M, Bar-Gad I. Tic Disorders: What Happens in the Basal Ganglia? Neuroscientist. 2013; 19(1):101-8.

4. Orth M, Münchau A, Rothwell JC. Corticospinal system excitability at rest is associated with tic severity in Tourette syndrome. Biol Psychiat. 2008; 64(3):248-51.

5. Rajagopal S, Seri and S, Cavanna AE. Premonitory urges and sensorimotor processing in Tourette syndrome. Behav Neurol. 2013; 27(1):65-73

6. Kataoka Y, Kalanithi PSA, Grantz H, Schwartz ML, Saper C, Leckman JF, et al. Decreased number of parvalbumin and cholinergic interneurons in the striatum of individuals with Tourette syndrome. The J Compar Neurol. 2010; 518(3):277-91.

7. Kalanithi PSA, Zheng W, Kataoka Y, DiFiglia M, Grantz H, Saper $\mathrm{CB}$, et al. Altered parvalbumin-positive neuron distribution in basal ganglia of individuals with Tourette syndrome. Proceedings of the National Academy of Sciences of the United States of America. 2005; 102(37):13307-12.

8. Lerner A, Bagic A, Simmons JM, Mari Z, Bonne O, Xu B, et al. Widespread abnormality of the $\gamma$-aminobutyric acid-ergic system in Tourette syndrome. Brain. 2012; 135(6):1926-36.

9. Piacentini J, Woods DW, Scahill L, Wilhelm S, Peterson AL, Chang $\mathrm{S}$, et al. Behavior therapy for children with Tourette disorder. JAMA. 2010; 303(19):1929-37.

10. Roessner V, Plessen K, Rothenberger A, Ludolph A, Rizzo R, Skov $\mathrm{L}$, et al. European clinical guidelines for Tourette syndrome and other tic disorders. Part II: pharmacological treatment. Eur Child Adolesc Psychiat. 2011; 20(4):173-96.

11. Scahill L, Erenberg G, Berlin Jr CM, Budman C, Coffey BJ, Jankovic $\mathrm{J}$, et al. Contemporary Assessment and Pharmacotherapy of Tourette Syndrome. NeuroRX. 2006; 3(2):192-206.

12. Tourette's Syndrome Study Group. Short-term versus longer term pimozide therapy in Tourette's syndrome. Neurology. 1999; 52: 874-7.

13. Müller-Vahl KR, Krueger D. Does Tourette syndrome prevent tardive dyskinesia? Movement Disord. 2011; 26(13):2442-3.

14. Dion Y, Annabele L, Sandor P, Chouinard G. Risperidone in the treatment of Tourette syndrome: A double-blind, placebo-controlled trial. J Clin Psychopharm. 2002; 22:31-9.

15. Scahill L, Leckman JF, Schultz RT, Katsovich L, Peterson BS. A placebo-controlled trial of risperidone in Tourette syndrome. Neurology. 2003; 69:1130-5.

16. Peña MS, Yaltho TC, Jankovic J. Tardive dyskinesia and other movement disorders secondary to aripiprazole. Movement Disord. 2011; 26(1):147-52.

17. Scahill L, Chappell PB, Kim YS, Schultz RT, Katsovich L, Shepherd $\mathrm{E}$, et al. A placebo-controlled study of guanfacine in the treatment of children with tic disorders and ADHD. Am J Psychiatry. 2001; 158: 1067-74.

18. Leckman JF, Hardin MT, Riddle MA, Stevenson J, Ort SI, Cohen DJ. Clonidine treatment of Gilles de la Tourette syndrome. Arch Gen Psychiatry. 1991; 48:324-8.

19. Porta M, Sassi M, Cavallazzi M, Fornari M, Brambilla A, Servello D. Tourettes Syndrome and Role of Tetrabenazine: Review and Personal Experience. Clin Drug Invest. 2008; 28(7):443-59. 
20. Kenney CJ, Hunter CB, Mejia NI, Jankovic J. Tetrabenazine in the treatment of Tourette syndrome. J Ped Neurol. 2007; 5(1):9-13.

21. Jimenez-Shahed J, Jankovic J. Tetrabenazine for treatment of chorea associated with Huntington's disease and other potential indications. Expert Opinion on Orphan Drugs. 2013; 1(5):423-36.

22. Jankovic J, Jimenez-Shahed J, Brown LW. A randomised, doubleblind, placebo-controlled study of topiramate in the treatment of Tourette syndrome. J Neurol Neurosur Ps. 2010; 81(1):70-3.

23. Kurlan R, Crespi G, Coffey B, Muller-Vahl K, Koval S, Wunderlich G, Pramipexole for TS Trial Investigators. A multi-center randomized placebo-controlled trial of pramipexole in Tourette's syndrome. Movement Disord. 2012; 27:775-8.

24. Kwak CH, Hanna PA, Jankovic J. Botulinum toxin in the treatment of tics. Arch Neurol. 2000; 57(8):1190-3.

25. Simpson DM, Blitzer A, Brashear A, Comella C, Dubinsky R, Hallett $\mathrm{M}$, et al. Assessment: Botulinum neurotoxin for the treatment of movement disorders (an evidence-based review). Neurology. 2008; 70(19):1699-706.

26. Maciunas RJ, Maddux BN, Riley DE, Whitney CM, Schoenberg MR, Ogrocki PJ, et al. Prospective randomized double-blind trial of bilateral thalamic deep brain stimulation in adults with Tourette syndrome. J Neurosurg. 2007; 107(5):1004-14.

27. Servello D, Porta M, Sassi M, Brambilla A, Robertson MM. Deep brain stimulation in 18 patients with severe Gilles de la Tourette syndrome refractory to treatment: the surgery and stimulation. $\mathrm{J}$ Neurol Neurosur Ps. 2008; 79(2):136-42.

28. Viswanathan A, Jimenez-Shahed J, Baizabal Carvallo JF, Jankovic J. Deep brain stimulation for Tourette syndrome: target selection. Stereotactic and Functional Neurosurgery. 2012; 90(4):213-24.

29. Tourette's Syndrome Study Group. Treatment of ADHD in children with Tourette's syndrome (TACT Trial). Ann Neurol. 2000; 48:953

30. Gadow KD, Sverd J, Nolan EE, Sprafkin J, Schneider J. Immediaterelease methylphenidate for ADHD in children with comorbid chronic multiple tic disorder. J Am Acad Child Adolesc Psychiatry. 2007; 46(7):840-8.

31. Allen AJ, Kurlan RM, Gilbert DL, Coffey BJ, Linder SL, Lewis DW, et al. Atomoxetine treatment in children and adolescents with ADHD and comorbid tic disorders. Neurology. 2005; 65(12):1941-9. 